${ }^{1}$ - инструментальная АЭС ИСП; ${ }^{2}$ - инструментальная МС ИСП; ${ }^{3}-$ ЭТИ АЭС ИСП; ${ }^{4}$ - комбинированная АЭС ИСП; ${ }^{5}$ - комбинированная МС ИСП.

Используя разработанный комплекс методик может быть охарактеризован кадмий чистотой 6N4 (99,99994 \%) по содержанию 58 примесей.

\title{
ИСПОЛЬЗОВАНИЕ ЭЛЕКТРОТЕРМИЧЕСКОГО ИСПАРЕНИЯ ПРОБ ПРИ ИСП-МС И ИСП-АЭС АНАЛИЗЕ ВЕЩЕСТВ ВЫСОКОЙ ЧИСТОТЫ
}

Медведев Н.С., Сапрыкин А.И. ИНХ СО РАН, Новосибирск, Россия medvedev@niic.nsc.ru

DOI: 10.26902/UDL2020_19

Масс-спектрометрия с индуктивно связанной плазмой (ИСП-МС) и атомно-эмиссионная спектрометрия с индуктивно связанной плазмой (ИСП-АЭС) это высокоинформативные методы количественного химического анализа. Эти методы отличают многоэлементность, низкие пределы обнаружения аналитов и динамический диапазон 6-8 порядков величины.

Стандартный способ введения проб в ИСП при ИСП-МС и ИСП-АЭС анализе это пневматическое распыление растворов. Этот способ введения проб отличает простота использования, высокая стабильность аналитического сигнала и универсальность, однако он имеет ряд недостатков. К их числу относят малую эффективность использования анализируемого раствора (обычно она не превышает 1-2 \%) и необходимость существенного разбавления анализируемой пробы (как правило, более чем в $10^{3}$ раз). Это приводит к снижению сигналов аналитов, возрастанию сигнала контрольного опыта, повышению вероятности внесения неконтролируемых загрязнений, что ухудшает пределы обнаружения и ограничивает возможности методов ИСП-МС и ИСП-АЭС применительно к анализу веществ высокой чистоты.

Электротермическое испарение (ЭТИ) это альтернативный высокоэффективный способ введения проб в ИСП. Этот способ введения проб основан на испарении материала проб с нагреваемой подложки (как правило, это графитовая кювета). При использовании ЭТИ не требуется значительного разбавления пробы, а для анализа достаточно 10-50 мкл образца. Целью работы была оценка аналитических возможностей методов ЭТИ-ИСП-МС и ЭТИ-ИСП-АЭС применительно к анализу веществ высокой чистоты.

Показаны преимущества и ограничения использования ЭТИ при анализе высокочистых кадмия, молибдена, вольфрама, оксида германия. Выбраны инструментальные параметры ЭТИ-ИСП-МС и ЭТИ-ИСП-АЭС анализа. Изучено поступление аналитов и элементов основы проб в ИСП 
при различных программах нагрева ЭТИ. Применение раздельного (фракционного) испарения основы проб и аналитов позволило существенно снизить спектральные влияния. Предложены способы прямого ЭТИ-ИСПАЭС анализа твердых проб и ЭТИ-ИСП-АЭС анализа с предварительным концентрированием примесей отгонкой основы проб. Показано, что использование ЭТИ позволяет снизить пределы обнаружения аналитов на величины до двух порядков. Правильность результатов ЭТИ-ИСП-МС и ЭТИ-ИСП-АЭС анализа подтверждена экспериментами «введенонайдено» и сравнением с результатами, полученными независимыми методами.

\author{
СРАВНЕНИЕ ВОЗМОЖНОСТЕЙ ИСП-МС \\ С КВАДРУПОЛЬНЫМ МАСС-АНАЛИЗАТОРОМ \\ И ИСП-МС ВЫСОКОГО РАЗРЕШЕНИЯ \\ ПРИ ИЗОТОПНОМ АНАЛИЗЕ \\ ${ }^{1}$ Медведев Н.С., ${ }^{2}$ Потапов А.М., ${ }^{2}$ Отопкова П.А., ${ }^{1}$ Сапрыкин А.И. \\ ${ }^{1}$ ИНХ СО РАН, Новосибирск, Россия \\ ${ }^{2}$ ИХВВ РАН, Нижний Новгород, Россия \\ medvedev@niic.nsc.ru
}

DOI: 10.26902/UDL2020_20

Полиатомные интерференции это одно из ограничений метода массспектрометрии с индуктивно связанной плазмой (ИСП-МС) с квадрупольным масс-анализатором. Как правило, полиатомные интерференции вызваны ионами, образующимися из плазмообразующего газа и компонентов, входящих в состав анализируемых растворов. Сигналы полиатомных ионов накладываются на сигналы аналитических изотопов, в результате происходит существенное возрастание фонового сигнала, значительное ухудшение пределов обнаружения и, в ряде случаев, невозможность проведения количественных измерений. Один из способов снижения полиатомных интерференций это использование реакционностолкновительных ячеек. Для эффективного снижения интерференций необходима оптимизация инструментальных параметров работы ячейки.

Спектрометры высокого разрешения с магнитным масс-анализатором обладают разрешением на уровне $\mathrm{n} \cdot 10^{3}$ и более, и лишены указанных ограничений, связанных с полиатомными интерференциями. Стоит отметить, что в ряде случаев при увеличении разрешения возможно снижение чувствительности. Кроме того, ИСП-МС спектрометры высокого разрешения менее распространены и требуют более высокой квалификации для их эксплуатации. Важной задачей при ИСП-МС анализе изотопно обогащенных материалов является правильный выбор концентрации анализируемых растворов для того, чтобы измеряемые сигналы аналитических изотопов соответствовали динамическому диапазону детектора. 